\title{
Ética e Sociedade
}

\author{
Oswaldo Giacoia Junior ${ }^{1}$ \\ Unicamp - IFCH - Departamento de Filosofia
}

resumo: Partindo de considerações sobre a modernidade cultural e o Esclarecimento, o texto estabelece uma relação entre direito ambiental e a tradição antropocêntrica da ética ocidental. Numa perspectiva crítica, passa depois a especular sobre o que poderia ser ambientalismo num horizonte ético em que se reconhecesse um direito próprio à natureza.

palavras-chave: Ética, Natureza, Sociedade, Esclarecimento.

abstract: Starting from considerations about cultural modernity and the Enlightenment, this paper establishes a relationship between environmental rights and the anthropocentric tradition of Western ethics. In a critical view, it speculates on what environmentalism could be within an ethical horizon which guaranteed nature its own rights.

keywords: Ethics, Nature, Society, Enlightenment.

A moderna racionalidade técnico-científica encontrou sua melhor formulação programática em alguns textos filosóficos que, com justiça, podem sustentar a pretensão de figurar como instauração magna da época das Luzes. No The New Organon, de Francis Bacon (1960, p.267, tradução nossa), por exemplo, lemos:

Assim, como probos e fiéis tutores, faremos finalmente entrega aos homens de sua fortuna, uma vez que seu entendimento esteja emancipado e tenha alcançado a maioridade. A isso se seguirá necessariamente a melhoria da situação humana e a ampliação de seu domínio sobre a natureza. Com efeito, por causa do pecado, o homem decaiu de seu estado de inocência e do seu reinado sobre as criaturas. Entretanto, uma e outra coisa podem ser reparadas, em parte, nesta vida: a

${ }^{1}$ E-mail: giacoia@tsp.com.br 
primeira, mediante a religião e a fé; a segunda, pelas artes e as ciências, pois a maldição não tornou a criatura completamente rebelde até o extremo. Ao contrário: em virtude daquele decreto, segundo o qual 'ganharás o pão com o suor da tua fronte', por meio de diversos trabalhos (por meio de diversos trabalhos, não por meio de disputas, certamente, ou mediante vãs cerimônias mágicas), ela se vê obrigada a conceder o pão à humanidade; o pão, isto é, os meios de vida.

No mesmo diapasão, na Instauratio Magna, Bacon procura restaurar a natural relação adequada entre o espírito humano e a realidade, prejudicada pelos falsos ídolos. Ele acreditava que o intelecto inflige a si mesmo imensos danos quando, pela ignorância da realidade, deixa de se valer dos métodos e recursos de que pode dispor (BACON, 1965, p.213). A restauração dessa relação tem por propósito o domínio do homem sobre a natureza, que é também a meta da própria ciência. Para ele, ciência e poder humano se identificam, pois onde a causa é desconhecida, seu efeito não pode ser gerado. Para dominar a natureza, é necessário obedecer à mesma, e o que é causa na observação, torna-se a regra na repetição (BACON, 1960, p.257).

Por sua vez, e situado no extremo oposto do empirismo inglês embora comungando com ele no mesmo espírito otimista -, o racionalismo cartesiano dá voz àquela mesma certeza de Bacon, à consciência de que já era passado o tempo das estéreis disputas escolásticas, de que se tratava, então, de proclamar a virtude emancipatória de uma ciência nova:

Mas, tão logo adquiri algumas noções gerais relativas à Física, e, começando a comprová-las em diversas dificuldades particulares, notei até onde podiam conduzir, e o quanto diferem dos princípios que foram utilizados até o presente, julguei que não podia mantê-las ocultas sem pecar grandemente contra a lei que nos obriga a procurar, no que depende de nós, o bem geral de todos os homens. Pois elas me fizeram ver que é possível chegar a conhecimentos que sejam muito úteis à vida, e que, em vez dessa Filosofia especulativa que se ensina nas escolas, se pode encontrar uma outra prática, pela qual, conhecendo a força e as ações do fogo, da água, do ar, dos astros, dos céus e de todos os outros corpos que nos 
cercam, tão distintamente como conhecemos os diversos misteres de nossos artífices, poderíamos empregá-los da mesma maneira em todos os usos para os quais são próprios, e assim nos tornar como que senhores e possuidores da natureza. (DESCARTES, 1983, p.63).

Ainda que situados em extremos opostos do arco teóricoepistemológico, concordavam plenamente quanto às virtudes emancipatórias da ciência e da técnica. O conhecimento não somente liberta a humanidade da ignorância e superstição, como também torna o homem senhor e possuidor das forças da natureza. Um pouco mais tarde, em dezembro de 1783, quando os sazonados frutos do Esclarecimento tornavam-se figuras do mundo sob a forma das Revoluções americana e francesa, Kant recolhia numa fórmula a definição essencial do espírito das Luzes: "Esclarecimento é a saída do homem de sua menoridade, da qual ele próprio é culpado. A menoridade é a incapacidade de fazer uso de seu entendimento sem direção de outro indivíduo" (KANT, 1985, p.100). Consolida-se, então, a aliança epocal entre o desenvolvimento da ciência e da técnica com as possibilidades de progresso material que traz consigo - e as exigências emancipatórias de progresso moral, ético e político do gênero humano, aliança que, muito tempo antes de Kant tê-la apreendido na fórmula do sapere aude, tinha sido formulada na França do século XVIII, entre outros, por D’Alembert e Diderot - para quem a Encyclopédie (esse fruto e filha dileta da Aufklärung francesa) deveria revolucionar o modo tradicional de vida, elevando as novas gerações à altura do desenvolvimento geral já alcançado pela humanidade.

Crê-se, pois, que, desde os pioneiros da moderna Aufklärung, na base de seu credo científico, vigora também, como elemento fundamental, um otimismo triunfalista, de acordo com o qual o intelecto humano, emancipado de toda tutela e vassalagem - com base na ciência e na técnica, que dela decorre -, coloca-se em condições de enfrentar e resolver com sucesso os mais importantes problemas humanos, de modo a garantir seu domínio sobre as forças da natureza, assim como de realizar a justiça nas relações entre os homens.

Assim, o progresso do gênero humano é o resultado de uma combinação inseparável entre, por um lado, o desenvolvimento do 
conhecimento teórico e da apropriação técnico-pragmática da natureza e, por outro lado, de sua utilização em benefício da dimensão ético-moral do ser humano, esta última essencialmente compreendida em referência a valores como autonomia, dignidade, justiça. Nessa chave, o eixo do programa social e ético-político do Esclarecimento, desde o início do movimento, integrava a promoção material e a elevação moral do homem por meio do livre uso da razão, em particular da racionalidade tecnocientífica, em sua forma moderna e experimental.

Senhor da ciência e da técnica, o homem poderia doravante tomar integralmente nas próprias mãos a planificação e o controle das condições de existência no planeta. $\mathrm{Na}$ era da escalada planetária da técnica, nossa civilização teria enfim transformado em realidade o significado daquela profética sentença em que Nietzsche resumia o cânone científico moderno: de acordo com ele, a razão, guiada pelo fio condutor da causalidade, seria capaz de não somente desvendar todos os enigmas do universo, mas também de corrigi-los (NIETZSCHE, 1980, p.97 e ss.).

Contudo, agudos observadores filosóficos da realização do programa há muito detectaram a incômoda presença de nuvens sombrias e carregadas a turvar o céu radiante do Esclarecimento. Nietzsche foi, certamente, um desses precursores. Mais próximos de nós, podemos nos referir a pensadores que, em geral, encontram-se situados em extremos opostos do arco ideológico do pensamento contemporâneo. Assim, por exemplo, em apontamentos coligidos entre 1936 e 1946, que deram origem ao ensaio denominado Überwindung der Metaphysike (Superação da Metafísica), Martin Heidegger antecipara reflexivamente, com aguçada percepção, o que viria a se transformar na realidade desconcertante de nossos dias, a saber, a produção técnico-científica e industrial da vida.

Uma vez que o homem é a mais importante matéria-prima, pode-se contar com que, com base nas pesquisas químicas atuais, serão instaladas algum dia fábricas para a produção artificial de material humano. As pesquisas do químico Kuhn, distinguido esse ano com o prêmio Goethe da cidade de Frankfurt, já abrem a possibilidade de dirigir planificadamente a produção de seres vivos machos e fêmeas, de acordo com as respectivas demandas. (HEIDEGGER, 1985, p.91, tradução nossa). 
Da mesma maneira como os progressos alcançados no domínio da física nuclear e da química transformaram o homem no "senhor dos elementos" (HEIDEGGER, 1985, p.88), desarraigando-o da 'terra' para projetá-lo na exploração do espaço intergaláctico, os avanços da tecnociência na área da bioquímica e da biologia molecular permitem decifrar os mapas genéticos responsáveis pela estruturação dos organismos superiores. Com isso, ter-se-ia completado, afinal, a sempre sonhada supremacia humana sobre as demais criaturas do universo. Dominando a ciência e a técnica, o homem poderia doravante tomar integralmente nas próprias mãos a planificação e o controle das condições de existência no planeta. Contudo, cabe suspeitar, tratar-se-ia do senhor dos elementos, ou da mais valiosa matéria-prima no processo de produção industrial da vida?

Por sua vez, já na abertura de sua Dialética do Esclarecimento, Horkheimer e Adorno (1987, p.25, tradução nossa) constatam:

Desde sempre o Esclarecimento, no sentido mais abrangente do pensamento em progresso, perseguiu a meta de retirar dos homens o medo e instaurá-los como senhor... O programa do Esclarecimento era o desencantamento do mundo. Ele queria dissolver o mito e derrubar a imaginação pelo saber. Bacon, 'o pai da filosofia experimental', já tinha reunido os motivos. Ele despreza os adeptos da tradição, que 'primeiramente acreditam que outros sabem o que eles não sabem; e depois, que eles próprios sabem o que eles não sabem.

No entanto, do ponto de vista do pensamento e da crítica da sociedade, há que se observar que, se desde o início e no mais amplo sentido, o programa do Esclarecimento consistiu em instaurar o homem como senhor da natureza, libertando-o das amarras do medo mítico e ancestral, a realização histórica e concreta desse programa teria resultado no contrário de sua meta, pois hoje não haveria como negar que "a terra completamente esclarecida resplandece no signo do infortúnio triunfal" (HORKHEIMER; ADORNO, 1987, p.25.). Essa passagem contém in nuce todos os indicativos dos compromissos espúrios entre a razão completamente esclarecida, a barbárie mítica e a dominação integral, levada a efeito pela tirania compulsiva da administração total da vida. 
Tentando tomar a sério, para nossa discussão atual, as análises e o diagnóstico da modernidade tal como formulados por Heidegger, qq Adorno e Horkheimer, não nos seria lícito formular a suspeita de uma dialética perversa conduzindo a realização do programa do Esclarecimento? De uma dinâmica de acordo com a qual o desenvolvimento histórico que leva à escalada planetária do domínio técnico-científico da natureza - realizando plenamente uma de suas vertentes emancipatórias - colide frontalmente com a exigência de irrestrita necessidade de liberdade de pensamento e investigação - outra de suas metas essenciais?

$\mathrm{Na}$ presente comunicação, gostaríamos de refletir sobre esse dilema partindo, inicialmente, de alguns exemplos extraídos dos mais recentes desenvolvimentos da ciência e da tecnologia; eles talvez nos pudessem fornecer alguma luz para recolocar, em novo patamar, a atualidade dos impasses entrevistos por Heidegger e pelos frankfurtianos. Pensemos, em primeiro lugar, nos prodigiosos recursos proporcionados pelas recentes descobertas nos domínios da química e da farmacologia, com seus efeitos fabulosos sobre a mente e o corpo. Com auxílio deles, não apenas defeitos e carências somatopsíquicas podem ser compensados, eliminando sofrimentos e frustrações, como também virtualidades podem ser superlativamente intensificadas, otimizando desempenhos e rendimentos.

Pensemos em seguida nos estudos atuais nas áreas das engenharias avançadas, sobretudo em ciências da computação e informática - em seu acoplamento com as pesquisas sobre inteligência artificial e, por extensão, com a neurofisiologia e a psicologia experimental. Aqui seria pertinente lembrar o crescente avanço no estudo dos fenômenos mentais, tornado possível pela reprodução artificial das principais operações lingüísticas e cognitivas do cérebro humano, obtidas graças à conexão entre o sistema neurológico e redes de computadores.

Por outro lado, a implantação experimental de chips de computador em cérebros de animais já permite, atualmente, reprodução tecnológica, em laboratório, de processos intencionais. Em associação com isso, convém recordar que essa interação do cérebro humano com suas reproduções artificiais já permite, em alguns casos, que o sistema nervoso 
central receba diretamente das máquinas o que uma deficiência dos órgãos dos sentidos, como a visão, por exemplo, não permite suprir.

Tais recursos podem potencializar, em escala inimaginável, as faculdades e as disposições 'naturais' do organismo humano, de modo que o cyberman é muito mais que ficção científica. Razão adicional a dar sustentação à tese daqueles que consideram que teríamos franqueado o limiar de uma nova era: a da autotransformação da espécie humana, ou o advento dos pósbumanos.

Sigamos avante nessa direção e consideremos as ilimitadas possibilidades e perspectivas que a decodificação e recombinação dos genomas significam para a inesgotável engenharia do homo faber. Ou seja: ao descobrirmos as regras de construção dos seres naturais, tanto no domínio humano quanto inumano, colocamo-nos, com isso, em condições de poder objetivá-las e manipulá-las, e assim, nos tornarmos também co-autores, ou parceiros na criação. Sobre esse aspecto do progresso técnico-científico atual se concentrará um pouco mais nossa atenção doravante, pois por meio dele tornar-se-á mais claro o questionamento que gostaríamos de formular.

Enunciemos, ainda que precariamente, o problema do seguinte modo: os processos e eventos que acima apresentamos não indicariam também que teríamos alcançado, com todos esses progressos, também o perigoso limiar em que a completa autodeterminação da razão científica se vê convertida em seu próprio contrário, quando considerada sob o ponto de vista ético? Isto é, ao assimilarmos os processos naturais a artefatos construídos pela capacidade de produção tecnológica, não teríamos, desse modo, 'perdido' o sentido tradicional de natureza, já que o natural sempre foi compreendido como aquilo que cresce por si mesmo (physis), diferindo dos produtos do fazer humano (techne)?

Aplicando esse raciocínio à natureza humana, ao objetivá-la num saber tecnocientífico, não a tornaríamos disponível para a operacionalização de meios com vistas a fins, característica da racionalidade instrumental, privando-a de sua autocompreensão ética tradicional, ligada a valores universais humanistas, como autonomia e dignidade?

Com isso, não estaria rompida a antiga aliança entre o progresso do conhecimento científico e a promoção-elevação ético-moral do gênero humano, que constituía um dos apanágios do Esclarecimento, de Bacon e 
Descartes a Diderot e Kant? Afinal, convém não esquecer que a fórmula kantiana referente à dignidade da pessoa como fim em si, já evocada no início do presente trabalho, encontrou seu correspondente histórico em quase todas as declarações de direitos e garantias fundamentais que abrem as constituições dos modernos estados democráticos de direito.

Acompanhando a sucinta formulação do problema pelo filósofo Slavoj Zizek (2003, p.4), pode-se dizer que

a principal conseqüência dos avanços da biogenética é o fim da natureza: ao conhecermos as regras de sua construção, os objetos naturais se tornam objetos disponíveis e manipuláveis. A natureza, humana e inumana, é assim 'dessubstancializada', privada de sua impenetrável densidade, daquilo que Heidegger chamou de 'terra'. A biogenética, com sua redução da própria psique humana a um objeto de manipulação tecnológica, é portanto efetivamente uma espécie de instância empírica do que Heidegger via como o 'perigo' inerente à tecnologia moderna.

Perigo de quê, propriamente, caberia perguntar? Perigo de que a natureza humana se torne objeto da técnica e de que a base somática da personalidade possa ser instrumentalizada para fins incompatíveis com o conjunto de valores e princípios éticos que, até aqui, forneceram ao gênero humano os elementos essenciais de sua autocompreensão.

Com efeito, não pode deixar de transtornar completamente nosso auto-entendimento como sujeitos éticos o conhecimento irrefutável de que os talentos e as virtudes que, até então, justificavam nossa realização como pessoas e legitimavam nossos padrões de reconhecimento social e autoestima - portanto, as condições de que tem historicamente dependido a consciência de nossa própria dignidade - resultam muito menos de nossos próprios méritos, de nosso trabalho, aplicação e esforço pessoal, do que dos níveis de determinadas substâncias químicas (como a serotonina, por exemplo) no sistema nervoso. Ora, sendo assim, passa a fazer sentido perguntar: por que razão não fazer uso dos recursos químicofarmacológicos mais modernos para compensar e corrigir um eventual contingente e arbitrário - déficit de provisão no equipamento natural? 
Quando SABEMOS que meu 'talento natural' depende de uma substância química em meu cérebro, realmente importa, moralmente, se eu o obtive do exterior ou ao nascer? Para complicar ainda mais as coisas: E se minha própria disposição para me dedicar ao esforço interior, à disciplina e ao trabalho duro depender de uma substância química? E se, para vencer um concurso, eu não tomar diretamente uma droga que reforça minha memória, mas 'simplesmente' uma droga que reforce meu empenho e minha dedicação? (ZIZEK, 2003, p.6 ).

Em ligação e como desdobramento dessa questão, pode ser muito ilustrativa e pertinente a referência às posições atuais do filósofo Jürgen Habermas sobre as pesquisas avançadas no domínio da biogenética. Para Habermas, as atuais pesquisas biotécnicas com embriões e genoma poderiam abrir caminho para uma intervenção eugênica positiva, no sentido de uma produção tecnológica da vida, para além dos limites restritivos, determinados pelo interesse terapêutico de identificar, prevenir e/ou tratar eficazmente patologias geneticamente causadas. Um dos riscos maiores dessa virtual 'fabricação' do design genético humano seria a possibilidade, por ela franqueada, de submeter o patrimônio genético de seres humanos à lógica e à dinâmica de preferências narcisistas individuais, ao arbítrio de consumidores habilitados para atuar num mercado virtualmente florescente.

Quando se acrescenta a isso que médicos out siders já trabalham hoje na clonagem reprodutiva de organismos humanos, impõe-se a perspectiva de que a espécie humana em breve poderia tomar nas próprias mãos sua evolução biológica. 'Parceiros da evolução', ou até 'brincar de Deus' são metáforas para uma, como parece, autotransformação da espécie em extensão iminente. (HABERMAS, 2001 b, p.42, tradução nossa).

Rompendo a simetria entre os programadores e os programados, a engenharia genética viria a subverter o plano tradicional de reciprocidade e reversibilidade nas relações entre pessoas, consideradas como agentes morais, as quais se encontram profundamente ancoradas em princípios religiosos, éticos e jurídicos. Com isso, estaria franqueada a perspectiva de 
uma instrumentalização em grande estilo das condições de existência humana.

Para Habermas, muito mais preocupantes do que extravagâncias de (má) ficção científica são os precedentes contemporâneos concretos, como os diagnósticos de pré-implantação, a produção e consumo experimental de embriões em procedimentos científicos, as possibilidades de decifração e recombinação de cadeias genéticas, com objetivos de intervenção seletiva, que ultrapassam e tornam instáveis as fronteiras entre pesquisa genética com fins terapêuticos (evitar os sofrimentos exorbitantes) e engenharia genética, que produz tecnologia para transformação qualitativa de características biológicas.

Para Habermas, não se pode oferecer uma resposta normativa satisfatória para tais problemas, recorrendo às proteções e garantias juridicamente estabelecidas nas declarações constitucionais de direitos humanos, ou a argumentos tradicionais, fundados na dignidade da pessoa. Com efeito, "sob as condições do pluralismo de cosmovisões, não podemos atribuir 'desde o início' ao embrião a 'proteção absoluta de vida' de que gozam pessoas como portadoras de direitos fundamentais" (HABERMAS, 2001 b, p.78).

Portanto, uma proteção absoluta, fundada no conceito de dignidade da pessoa como sujeito moral e jurídico, é uma prerrogativa que, sem que se incorra em petições de princípios metafísicos e substancialistas - ou sem recorrer a artigos de fé religiosa -, não pode ser estendida a uma situação e condição existencial de que ainda está ausente a personalidade, no pleno sentido do termo.

É por essa razão que, segundo Habermas (2001 b, p.72-80), o argumento contrário à instrumentalização da vida humana por uma eugenia liberal não deve ser buscado direta e imediatamente no âmbito jurisdicional ou constitucional - portanto, no plano da proteção assegurada às pessoas -, mas num limiar bem mais recuado e fundamental: no terreno normativo das intuições, sentimentos, convicções e razões que estão na base da moral racional dos direitos humanos. Esse plano, por assim dizer infrajurídico, é denominado pelo autor autocompreensão ética da espécie, na medida em que esta é partilhada por todas as pessoas morais. 
A partir dessa perspectiva impõe-se a pergunta sobre se a tecnização da natureza humana altera a autocompreensão ética, própria da espécie, de tal modo que nós não podemos mais nos compreender como seres vivos, livres e moralmente iguais, orientados por normas e fundamentos. Só com o surgimento imprevisto de alternativas surpreendentes fica abalada a auto-evidência de hipóteses de fundo (HABERMAS, 2001 b, p.74, tradução nossa).

E, a partir dessa preocupação, Habermas (2001 b, p.76-77, tradução nossa) complementa:

A manipulação da composição do genoma humano, em larga medida decifrado, e a expectativa de alguns geneticistas de poder tomar de imediato a evolução em suas próprias mãos abalam, de qualquer modo, a diferenciação categorial entre subjetivo e objetivo, entre aquilo que cresce naturalmente e aquilo que é produzido, naquelas regiões até agora subtraídas à nossa disponibilidade. Trata-se da indiferenciação biotécnica de distinções categoriais profundamente enraizadas, que tínhamos até agora presumido como invariantes. Isso poderia alterar de tal maneira nossa auto-compreensão ética, própria da espécie, que com isso seria afetada também nossa consciência moral - a saber, as condições de crescimento natural sob as quais unicamente podemos nos compreender como autores de nossas próprias vidas e como membros igualmente legitimados da comunidade moral. Suspeito que o conhecimento da programação do próprio genoma poderia perturbar a evidência com a qual existimos como corpo, ou em certa medida 'somos' nosso corpo, e que com isso surge também um novo tipo de peculiar relação assimétrica entre pessoas.

A questão em torno da necessidade de limites morais impostos ao projeto de eugenia liberal passa, portanto, aos olhos de Habermas, por duas pressuposições que afetam essencialmente o substrato ético de autocompreensão das pessoas, consideradas como fins em si mesmas: a possibilidade de uma condução autônoma da vida e as condições de um tratamento recíproco e igualitário com outras pessoas.

A disposição arbitrária sobre a configuração genética de uma outra pessoa fundaria uma relação interpessoal desconhecida até agora entre o gerador e o 
gerado, entre o modelo e a cópia genética. Essa relação de dependência diverge das conhecidas relações interpessoais à medida que ela subtrai a possibilidade de transformação em uma relação entre iguais, entre posicionados normativamente iguais e tratados de modo igual. O designer fixa de modo irrevogável e assimétrico a figura inicial do seu produto - fundamentalmente sem deixar aberta a possibilidade de uma troca de papéis (HABERMAS, 2001a, p.218).

Por isso, a conclusão de Habermas é que a irreversibilidade de uma decisão tomada por outrem sobre o nascimento de uma pessoa, com efeito contínuo sobre a existência desta, afeta a possibilidade de autocondução autônoma de sua existência: “[...] a autocompreensão moral se modifica assim que a pessoa atribui o fundamento natural de seu desenvolvimento a uma outra pessoa, porque ela encontra um propósito alheio na imagem das próprias disposições" (HABERMAS, 2001a, p.218s).

Podemos perceber claramente que tais posições decorrem de uma reconstrução do universalismo moral kantiano, nos moldes e de acordo com os pressupostos da teoria do agir comunicativo, particularmente de uma reinterpretação da noção kantiana de dignidade da pessoa como 'fim em si'. São esses pressupostos, como se percebe, que a possibilidade da eugenia positiva desestabiliza.

A 'fórmula do fim em si' do imperativo categórico contém a exigência de considerar cada pessoa 'ao mesmo tempo também como fim em si mesma', e nunca utilizá-la 'apenas como simples meio'. Os participantes [de uma prática comunicativa, OGJ, também em casos de conflito, devem prosseguir sua interação na posição do agir comunicativo. A partir da perspectiva do participante em primeira pessoa, eles devem se colocar na perspectiva do outro, como na de uma segunda pessoa, com o propósito de se entender com ela sobre alguma coisa, ao invés de objetivá-la, a modo da perspectiva observacional de uma terceira pessoa, instrumentalizando-a para suas próprias finalidades. A fronteira moralmente relevante da instrumentalização é marcada por aquilo que, diante de uma segunda pessoa, necessariamente se furta a todos os ataques da primeira pessoa, por tanto tempo quanto permanece em geral intacta a relação comunicativa; portanto pela possibilidade de resposta e posicionamento - por meio daquilo, pois, com o que e pelo que uma pessoa é ela mesma, quando age e contrapõe a seus críticos o 
discurso e a resposta. O 'si próprio' do fim em si, que devemos respeitar na outra pessoa, exprime-se especialmente pela autoria na condução de uma vida, que se orienta, a cada vez, por exigências próprias (HABERMAS, 2001 b, p.96).

É, portanto, contra esse pano de fundo, em que a moral racional dos direitos humanos se liga a uma autocompreensão ética, própria da espécie, que ganha legitimidade, para Habermas (2001 b, p.46), a exigência de limitar e subtrair à instrumentalização - por via normativa - aquilo que, por meio da ciência e da tecnologia, foi tornado disponível. A instrumentalização da vida humana pelas novas técnicas de pesquisa genética encontra sua barreira moral na possibilidade de rompimento do plano de simetria e reciprocidade exigido pelo status virtual de futuro participante no circuito do agir comunicativo, portanto, de futuro e potencial membro da comunidade moral.

Sobre esse ponto incide a crítica a Habermas por Slavoj Zizek. Desdobrando as implicações das teses de Habermas, afirma Zizek (2003, p.5):

Assim, basicamente, o que Habermas está dizendo é: embora hoje saibamos que nossas disposições dependem da insignificante contingência genética, vamos fingir e agir como se não fosse o caso, de modo a mantermos nosso sentido de dignidade e de autonomia - o paradoxo, aqui, é que a autonomia só pode ser mantida proibindo o acesso à cega contingência natural que nos determina, isto é, em última instância LIMITANDO a nossa autonomia e a liberdade de intervenção científica.

Não seria isso uma nova versão do antigo argumento conservador de que para mantermos nossa dignidade moral é melhor não saber certas coisas? Em suma, a lógica de Habermas é a seguinte: já que os resultados da ciência representam uma ameaça para nossa (noção predominante de) autonomia e liberdade, devemos reprimir a ciência - o preço que pagamos por essa solução é a separação fetichista entre ciência e ética ('Sei muito bem o que a ciência afirma; não obstante, para manter minha [aparência] de autonomia, prefiro ignorar e agir como se não soubesse'). Essa divisão nos impede de enfrentar a verdadeira pergunta: como essas novas condições nos forçam a transformar e reinventar as próprias noções de liberdade, autonomia e responsabilidade ética? 
Caminhando na direção indicada nessas últimas linhas, a conclusão de Zizek o situa no pólo simetricamente oposto àquele em que fica situado Habermas; com efeito, Zizek defende a completa objetivação do genoma humano. "Ao contrário de Jürgen Habermas, deveríamos assim afirmar a necessidade ética de assumirmos a plena objetivação do genoma: essa redução do meu ser substancial à fórmula insensível do genoma me força a atravessar o fantasmagórico 'étoffe du moi', o estofo de que são feitos nossos egos - e é somente através desse esforço que pode emergir a subjetividade propriamente dita" (ZIZEK , p.8).

Para os fins do presente trabalho, importa menos julgar a estrita correção da interpretação por Zizek dos argumentos teóricos e práticos de Habermas. Interessa mais verificar as conseqüências de sua crítica, feita à luz daquela exigência de repensar os princípios normativos e os valores tradicionalmente implicados no conceito de natureza humana.

A principal questão colocada por Zizek, em sua crítica a Habermas, contém também o enunciado do problema que escolhemos para discutir nesta oportunidade: os novos rumos do desenvolvimento tecnocientífico - especialmente nos domínios da bioquímica, da biologia molecular e da engenharia genética - produzem uma ruptura na antiga cumplicidade entre as dimensões lógico-cognitivas e ético-políticas fundidas pelos arautos do Esclarecimento.

Essa ruptura, por sua vez, produz uma conseqüência cujos efeitos mais dramáticos estão presentes nas dificuldades com que nos confrontamos ao tentar conciliar exigências fundamentais da modernidade que, atualmente, podem se confrontar sob a forma de um antagonismo: por um lado, assegurar a liberdade de investigação científica, como uma prerrogativa historicamente consolidada à qual não se pode nem se deve renunciar; por outro lado, compatibilizá-la com a proteção da dignidade da vida e da pessoa, enquanto princípios constitucionalmente garantidos pelo moderno estado democrático de direito.

Se, para os patronos do Esclarecimento, uma dessas vertentes promovia naturalmente o fomento da outra, para nós, elas tendem a se apresentar na forma de uma 'separação fetichista' entre ética e ciência, que nos impõe, como tarefa histórica, um esforço coletivo para refletir sobre as condições atuais da autonomia e da responsabilidade ética. Essa é também 
a razão pela qual as condições teóricas e práticas de produção da ciência moderna estão intimamente imbricadas na complexa rede de interesse do capital, das indústrias e dos Estados.

Tornada força produtiva e mesmo base do desenvolvimento da vida social e econômica, a pesquisa científica passa a ser vital para o funcionamento global da sociedade, razão pela qual não se pode mais prescindir da subvenção de suas pesquisas por grandes grupos econômicos e industriais. Isso pode ser constatado, por exemplo, pelos imensos aportes de recursos disponibilizados pela indústria químico-farmacêutica para a pesquisa científica, ou pelos exponenciais investimentos em pesquisa financiados pela indústria bélica, ou provenientes de fundos destinados a prover interesses estratégicos de segurança nacional.

As pesquisas mais avançadas na área das ciências formais, das linguagens artificiais de caráter lógico-matemático e os estudos melhor desenvolvidos nas ciências da computação são atualmente, em grande parte, subvencionados pela indústria da informática. Quando se pensa hoje em autonomia e responsabilidade, há que se considerar que o efetivo agente do progresso científico deixou de ser, em grande medida, o pesquisador individual.

Nesse ponto, seria indispensável inserir uma referência à posição lúcida e equilibrada de Hans Jonas. Para ele, o sujeito da produção científica atual é quase sempre um coletivo e, em certa medida, anônimo, representado pelos grupos e circuitos de pesquisa, integrados e sincronizados em nível internacional, especialmente pela rede global de computadores, mobilizando vultosas parcelas de capital internacional. Desse modo, as possibilidades de supervisão e controle sobre programas de pesquisa, bem como sobre a utilização mercadológica de seus resultados, são literalmente imponderáveis, sobretudo porque, nas condições impostas pelo modo atual de organização das sociedades avançadas, os setores mais importantes da vida social, em termos de produção, consumo e lazer, estão baseados na necessidade de atualização ou renovação permanente de seu potencial científicotecnológico, o que gera uma dinâmica autônoma do processo de aproveitamento industrial da pesquisa tecnológica.

Ora, desse modo, a cada nova descoberta técnico-científica, impõe-se uma necessidade compulsiva de sua utilização em escala 
econômico-industrial. É prudente considerar também que toda compulsão traz consigo um traço patológico de dependência, porque exclui a possibilidade de controle racional e, no limite, domina aqueles que acomete - no caso que ora nos interessa, transformando o pseudo-agente da produção tecnológica em escravo de seus próprios produtos.

A isso se vincula outro aspecto importante: os efeitos possivelmente danosos da intervenção científica sobre a natureza foram ampliados de maneira extraordinária, porque a potência destrutiva dos artefatos tecnológicos é proporcional ao seu potencial produtivo exponencial. Dada a imensa complexidade atual das teorias científicas, por maior que seja a extensão de nosso conhecimento, ele não nos capacita a prever inteiramente as conseqüências que podem resultar de sua aplicação experimental, menos ainda de sua utilização industrial em larga escala. Essa imprevisibilidade de efeitos irreversíveis, de proporções superlativas, constitui um agravante da responsabilidade, pois traz consigo o espectro da catástrofe ecológica, que transforma o antigo sonho de domínio em pesadelo e o apocalipse em devastação.

Ao refletir sobre uma ética adequada às condições atuais da civilização tecnológica, Jonas se esforça por colocar-se à altura precisamente desta espinhosa tarefa: a necessidade de se pensar em limites éticos - mas também jurídicos - para a pesquisa científica e tecnológica. Nesse campo, segundo Jonas, a primeira pergunta seria: até que ponto é eticamente justificável tornar indiscriminadamente disponível a base somática da personalidade humana? Quais seriam, para as futuras gerações de seres humanos, as conseqüências éticas e existenciais implicadas na modificação tecnológica das condições e referências tradicionais, que até hoje determinaram a autocompreensão e a auto-estima da humanidade, com inclusão de seus aspectos positivos e negativos, luminosos e sombrios?

Qual será o destino das futuras gerações humanas, caso seja mantida a direção e o ritmo dos progressos da ciência tecnológica? Seriam elas ainda humanas (no mesmo sentido em que aplicamos a nós mesmos esse termo)? Por outro lado, teriam as gerações futuras um direito eticamente sustentável - a tal existência? Tem sentido falar em direito de pessoas que ainda não existem? Seria esse um limite normativo eticamente 
defensável contra a extensão virtualmente ilimitada da produção técnicocientífica e de sua utilização industrial?

Esse é o conjunto de questões que marca a especificidade e a novidade radical da proposta de Jonas de uma ética para a civilização tecnológica. Para ele, não se pode perder de vista que, se houve sempre uma estreita relação entre saber e poder - e, no caso da ciência e da moderna tecnologia, essa relação adquire contornos especiais -, nas condições atuais, a capacitação tecnocientífica de uma faculdade, ou um poder de atuação, praticamente compele à necessidade de sua utilização.

Em geral, a posse de uma capacidade ou poder (por indivíduos ou grupos) não significa ainda sua utilização. Ela pode arbitrariamente permanecer em repouso por longo tempo para, ocasionalmente, segundo o desejo e, depois da ponderação do sujeito, entrar em atividade. Quem é lingüisticamente talentoso não precisa falar sem cessar e, considerando globalmente, pode até ser calado. Todo saber pode também, assim parece, reservar para si sua utilização. Todavia, essa relação tão óbvia entre poder e fazer, saber e utilização, posse e exercício de um poder não vale para o fundus de capacitação técnica de uma sociedade que, como a nossa, fundamentou sua inteira configuração da vida, em trabalho e ócio, sobre a atualização corrente de seu potencial técnico, considerado na ação conjunta de todas as suas partes. Aqui a coisa se iguala à relação entre poder respirar e ter que respirar, de preferência àquela entre poder falar e falar. E o que vale para o fundus presentemente disponível se estende a cada crescimento do mesmo: se esta ou aquela nova possibilidade foi alguma vez (na maioria das vezes por meio da ciência) aberta e desenvolvida, em ponto pequeno, [...] então ela traz em si o compelir à sua utilização, em ponto grande e sempre maior, e o tornar essa utilização uma permanente necessidade vital (GIACOIA JUNIOR, 1999, p.410).

Essa postura teórica nos coloca diante de uma exigência inaudita, que consiste em reconhecer e garantir um direito próprio à natureza, não somente humana. A defesa desse direito tem por fundamento uma recusa das modalidades mais comuns de justificação moral empregadas pelos vários humanismos que concorreram ou se sucederam ao longo da história recente de nossa civilização. Sem desconsiderar os legítimos interesses da investigação e do desenvolvimento científico, ela os pondera, no entanto, 
com uma indispensável dose de prudência haurida de uma experiência cultural que Hans Jonas, apropriadamente, denominou de heurística do temor.

Considerando que o estado atual do conhecimento técnicocientífico libera para o agir humano um potencial de forças tão extraordinário que altera a concepção tradicional de sua extensão e limites; considerando que os efeitos da intervenção tecnológica estão investidos de um poder cumulativo de destruição, cujas conseqüências podem ser, e de fato freqüentemente são, irreversíveis, então é necessário que se passe a incluir o conjunto da natureza na esfera de responsabilidade desse agir, sobretudo daquele que se situa no âmbito de competência da comunidade científica.

Esse é um elemento novo e desafiador, que implica o reconhecimento de subjetividade ética e jurídica para entes naturais não humanos, envolvendo a direta responsabilidade da comunidade científica em relação aos mesmos. Como conseqüência dessa exigência, o antropocentrismo arraigado em nossa cultura fica destituído da antiga hegemonia, pela qual o homem deveria ser visto como o sentido último e o coroamento da criação, o bem-estar humano devendo sempre ser tomado, em qualquer circunstância, como referência valorativa incondicional.

O projeto ético de Hans Jonas, desenvolvido em estreita colaboração e permanente diálogo com as mais avançadas pesquisas científicas atuais, não é endereçado a um sujeito ético monológico, tampouco ao círculo próximo dos parceiros envolvidos numa 'comunidade ideal de falantes'; seu arco de abrangência não se restringe apenas às relações entre seres humanos - até agora entendidos como os exclusivos sujeitos morais -, mas alarga-se o suficiente para incluir no horizonte ético da responsabilidade tanto as futuras e remotas gerações de seres humanos (portanto, de seres que ainda não são ou existem) quanto os suportes e recursos ecológicos e ambientais da vida na terra - para os quais é reclamado um direito próprio.

Essa ampliação de horizontes para uma responsabilidade não limitada aos interesses humanos - seja os da geração atual, seja das futuras - reúne

o bem humano com a causa da vida em sua totalidade, ao invés de contrapor, de maneira hostil, esses interesses e a causa da vida em geral. Seria necessário, então, 
conferir à vida extra-humana seu direito próprio. Seu reconhecimento significa que toda extinção arbitrária e desnecessária de espécies se torna já em si mesma um crime, em completa independência de idênticas considerações dos interesses humanos; e torna-se um dever transcendente para o homem proteger todos os 'recursos' menos reprodutíveis, os mais insubstituíveis de todos - aquele inacreditavelmente rico pool genético, deixado na seqüência dos eônios da evolução. É o excesso de poder que impõe ao homem esse dever; precisamente contra aquele poder; portanto, é imprescindível a proteção do homem contra o próprio homem. E assim ocorre que a técnica, essa fria obra pragmática da astúcia humana, introduz o homem num papel que apenas a religião por vezes lhe atribuiu: aquele de administrador e guardião da criação. Ao ampliar o poder de seus efeitos até o ponto em que este se torna manifestamente perigoso para a economia global das coisas, ela estende a responsabilidade do homem ao futuro da vida na terra, vida que doravante está exposta indefesa ao mau uso dessa potência (GIACOIA JUNIOR, p.413).

Essa passagem expõe a medula ética da nova postura teórica. Ela ilustra também, de maneira consistente, uma nova mentalidade em seu conjunto e, com toda a certeza, permite assegurar que dela decorrerão conseqüências de extraordinária relevância para a consolidação de um ethos científico cujos resultados inauguram novas perspectivas para o asseguramento de ampliados espaços de ação e reflexão.

Um argumento freqüentemente empregado para refutar a reivindicação de um direito próprio a ser conferido à natureza é que apenas seres racionais, dotados de linguagem articulada e comunicação - capazes, portanto, de se integrar numa comunidade de fala -, podem esperar e exigir uns dos outros reconhecimento mútuo de direitos e deveres normativamente fixados. Entretanto, não considero esse um argumento irrespondível. Ao contrário, pode-se replicar que há também casos múltiplos e variados de seres humanos nas mesmas condições, os quais nem por isso podem ser legitimamente destituídos da condição moral e jurídica de pessoas, portadoras do valor compreendido no conceito de dignidade humana.

No texto de Jonas citado logo acima, o homem figurava como despojado da orgulhosa pretensão a ser o 'senhor do universo', assumindo o papel mais humilde e não menos dignificante de 'gestor e guardião' da 
criação. Suas funções poderiam bem incluir a meritória tarefa de ser também o porta-voz daqueles que não podem, por si mesmos, fazer valer os próprios direitos.

\section{Referências}

BACON, Francis. The New Organon and Related Writings. Ed. Fulton H. Anderson. New York: Macmillan Publishing Company, 1960.

Opere Filosofiche. Ed. Enrico De Mas. Bari: Editore Laterza, 1965.

DESCARTES, René. Discurso do Método. 3. ed. Trad. de J. Guinsburg e Bento Prado Jr. São Paulo: Abril Cultural, 1983. (Os Pensadores).

GIACOIA JUNIOR, Oswaldo. Hans Jonas: Por que a técnica moderna é um objeto para a ética. Natureza Humana, São Paulo, v. 1, n. 2, p.407-420, dez. 1999.

HABERMAS, Jürgen. A pessoa clonada não seria um caso de dano ao direito civil. In: - A Constelação pós-nacional: Ensaios Políticos. Trad. de Márcio Seligmann-Silva. São Paulo: Littera Mundi, 2001. p.217-220.

Die Zukunft der menschlichen Natur. Auf dem Weg zu einer liberalen Eugenik? Frankfurt: Suhrkamp Verlag, 2001.

HEIDEGGER, Martin. Überwindung der Metaphysik. In: Vorträge und Aufsätže. Pfullingen: Neske, 1985. p.67-96..

HORKHEIMER, Max; ADORNO, Theodor. Dialektik der Aufklärung. In: HORKHEIMER, Max. Gesammelte Schriften. Ed. Alfred Schmidt und Gunzelin Schmid Noerr. Frankfurt: Fischer Verlag, 1987. Band 5. É um livro inteiro.

KANT, Immanuel. Resposta à Pergunta: Que é 'Esclarecimento'. In: Textos Seletos. Trad. de Raimundo Vier e Floriano S. Fernandes. Petrópolis: Vozes, 1985. É um livro inteiro.

NIETZSCHE, Friedrich. Sämtliche Werke. Kritische Studienausgabe (KSA). Ed. G. Colli und M. Montinari. Berlin: de Gruyter, DTV, 1980.

ZIZEK, Slavoj. A Falha da Bio-Ética. Trad. de Luiz Roberto Mendes Gonçalves. Folha de São Paulo, São Paulo, 22 jun. 2003. Caderno Mais!, p.4-8.

Artigo recebido em 22/10/2007 - Aprovado em 08/06/2008 